\title{
Open-Circuit Fault Diagnosis for Cascaded H-Bridge Multilevel Inverter Based on LS-PWM Technique
}

\author{
Gang ZHANG and Jingrong YU
}

\begin{abstract}
Multilevel inverters have been widely used in high voltage and high-power applications on account of their remarkable performance in recent years. The multilevel inverters have an increased chance of switch fault due to a considerably large number of semiconductor switches associated with the power conversion. Therefore it is crucial to detect and locate faults quickly. In this context, an open-circuit fault diagnosis method for cascaded H-bridge multilevel inverter (CHBMI) based on the level-shifted pulse width modulation (LS-PWM) technique is proposed. Unlike the fault diagnosis based on the algorithm, the proposed method only needs a certain logical judgment to diagnose the fault based on subtle fault characteristics. The output voltage of the H-bridge and load current are used for fault diagnosis.
\end{abstract}

Index Terms - Cascaded H-bridge multilevel inverter, fault diagnosis, level shifted pulse width modulation, open-circuit fault.

\section{INTRODUCTION}

$\mathrm{C}$ ASCADED H-bridge multilevel inverter (CHBMI) constructed by series-connected H-bridges, is a popular multilevel topology. Compared with the diode-clamped [1]-[3] and flying capacitor multilevel topologies [4]-[6], the topology of CHBMI is more suitable for the systems supplied by multiple independent DC sources. The CHBMI is composed of several cascaded monomers without using many diodes or capacitors, which reduces the cost of the system. It is highly modular and easy to implement and install when extending to higher voltage levels. The control of each cascade monomer can be independent of each other. The capacitor voltage imbalance is avoided, and the output waveform distortion rate is low. The power factor and efficiency of the system are very high, and the pollution to the grid is small. Therefore, the cascaded H-bridge inverter is widely used.

Transistors in CHBMI, mainly insulated gate bipolar transistors (IGBTs), could suffer from short-circuit (SC) and open-circuit (OC) faults [7]-[9]. Because the SC fault occurs quickly and is difficult to detect, the diagnosis and system protection of SC fault are mainly solved by hardware circuit design. The SC

Manuscript received April 30, 2021; revised July 6, 2021; accepted August 30, 2021. Date of publication September 30, 2021; date of current version September 24, 2021.

Both authors are with the College of Automation, Central South University, Changsha 410083, China.

Digital Object Identifier 10.24295/CPSSTPEA.2021.00018 fault can also be converted into an $\mathrm{OC}$ fault for processing by connecting the fast fuse to the circuit [10]. When the OC fault occurs, the system will operate continuously, which leads to some problems of non-fault power semiconductor devices such as flowing through more current, torque reduction, heating, and insulation damage. More severely, the whole system could be paralyzed [11]. At present, the research on fault diagnosis of multilevel inverters mainly focuses on $\mathrm{OC}$ faults. Therefore, it is significant to develop fast and accurate transistor OC fault diagnosis methods.

Transistor OC fault diagnosis methods can be generally categorized as current signal-based, voltage signal-based, and model-based methods. Current vectors [12], average currents [13], current reference errors [14], near-zero currents [15] and so on, can be utilized for transistor OC fault diagnosis. The fault diagnosis methods based on AC harmonic analysis are presented in [16], and the method based on current processed with an adaptive neuro-fuzzy inference system is proposed in [17]. The problems of these methods include slow diagnosis speed and low accuracy. The method based on the DC component of specific sampling current introduced in [18] can detect the faulty transistors, but this method can only be applied to the rectifying mode (RM), and the diagnosis time is also long.

Voltage signals, such as bridge arm pole voltages [19], bridge arm pole-to-pole (PTP) voltages [20], and gate voltages [21], can be used for transistor OC fault diagnosis. These methods can detect and identify the faulty transistor fast, but extra fault diagnosis circuits are needed, which increases cost, PCB size, and design complexity.

For the model, several model-based methods have been proposed for transistor OC fault diagnosis. An adaptive system is developed to observe the phase voltage distortions for diagnosis [22]. A dynamic model with mixed logic is built to estimate the deviations between the expected and the measured motor currents for fault identification [23]. In [24], a voltage observer is built to obtain the errors between the reference and the estimated output voltage. In [25], the current Luenberger observer model is implemented for diagnosis in back-to-back converters of permanent magnet synchronous generator (PMSG) drives. These methods have achieved significant advancements, but the detection speed still needs improvement, and the sampling frequency needs to be higher than the switching frequency, which would be an obstacle for application in high-frequency 
TABLE I

The Difference Between Schemes I ANd II

\begin{tabular}{cccccc}
\hline \hline & $\begin{array}{c}\text { The required } \\
\text { signal }\end{array}$ & $\begin{array}{c}\text { Detection } \\
\text { time (ms) }\end{array}$ & $\begin{array}{c}\text { Number of } \\
\text { sensors }\end{array}$ & $\begin{array}{c}\text { Number of } \\
\text { levels }\end{array}$ & $\begin{array}{c}\text { Increase of } \\
\text { switching } \\
\text { frequency }\end{array}$ \\
\hline Scheme I & $\begin{array}{c}\text { driving sig- } \\
\text { nals, voltage } \\
\text { or current } \\
\text { voltage and } \\
\text { current }\end{array}$ & $\begin{array}{c}0.11(\text { error } \\
3 \%)\end{array}$ & 3 & 5 & yes \\
Scheme II & around 0.4 & 2 & 3 & no \\
\hline
\end{tabular}

inverters.

The literature review shows that previous fault diagnosis methods may have some limitations, such as adding extra circuits, incapability of fault identification, high sampling frequency, and long diagnosis time. In order to handle these problems, this paper presents a fault diagnosis method based on the LS-PWM technique.

Table I shows the difference between the proposed method (Scheme I) and the prior state-of-the art scheme [26] (Scheme II).

The major contributions of this paper can be summarized as follows:

1) A new fault characteristic is discovered for the cascaded five-level inverter. After fault occurs, the output voltage of the bridge arm will completely vanish during specific half periods under other modulation methods, but only part of the output voltage of the bridge arm based on LS-PWM will vanish, which can be utilized for diagnosing. Driving signals are introduced as diagnostic variables at the same time.

2) The diagnosis logic is put forward according to the new fault characteristics.

3) The detection time is improved based on the LS-PWM technique.

4) The number of levels is increased.

5) The switching frequency is increased.

The rest of the paper is organized as follows: The principle of CHBMI and the analysis of fault characteristics based on the LS-PWM technique are given in Section II. The proposed fault diagnosis method are given in Section III. The results of the experiment are demonstrated in Section IV. Lastly, Section V summarizes the paper.

\section{The Principle of CHBMI and the Analysis of Fault Characteristics}

\section{A. Operating Principle of CHBMI}

The topological structure of a single-phase cascaded five-level inverter is shown in Fig. 1. The CHBMI includes two H-bridges, eight switches $\left(\mathrm{S}_{1}-\mathrm{S}_{8}\right)$ with healthy anti-parallel diode $\left(\mathrm{D}_{1}-\mathrm{D}_{8}\right)$, filter capacitor $C, \mathrm{DC}$ voltage source $U_{\mathrm{dc}}, \mathrm{LC}$ filter, and inductive load. $\mathrm{G}_{1}-\mathrm{G}_{8}$ are driving signals, respectively. In this paper, the CHBMI is controlled with a dual loop, where the output voltage of the H-bridge $\left(v_{\mathrm{o} 1}, v_{\mathrm{o} 2}\right)$ and load current $\left(i_{1}\right)$ are sampled for control. The relationship between the output voltage $v_{\mathrm{o}}$ and the switching state based on the LS-

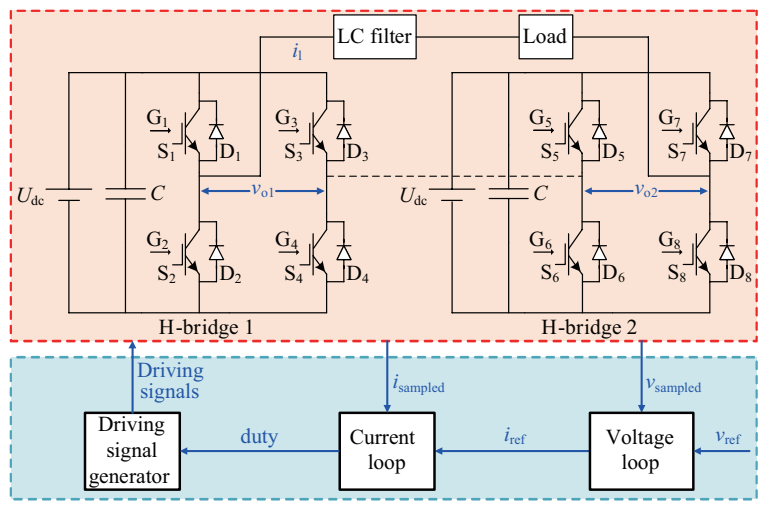

Fig. 1. The topological structure of single-phase cascaded five-level inverter.

TABLE II

ReLATIONShip BETWEen $V_{0}$ AND $S_{x}$

\begin{tabular}{lcccccccc}
\hline \hline$v_{\mathrm{o}}$ & $\mathrm{S}_{1}$ & $\mathrm{~S}_{2}$ & $\mathrm{~S}_{3}$ & $\mathrm{~S}_{4}$ & $\mathrm{~S}_{5}$ & $\mathrm{~S}_{6}$ & $\mathrm{~S}_{7}$ & $\mathrm{~S}_{8}$ \\
\hline $2 U_{\mathrm{dc}}$ & 1 & 0 & 0 & 1 & 1 & 0 & 0 & 1 \\
$U_{\mathrm{dc}}$ & 1 & 0 & 0 & 1 & 0 & 1 & 0 & 1 \\
0 & 0 & 1 & 0 & 1 & 0 & 1 & 0 & 1 \\
$-U_{\mathrm{dc}}$ & 0 & 1 & 1 & 0 & 0 & 1 & 0 & 1 \\
$-2 U_{\mathrm{dc}}$ & 0 & 1 & 1 & 0 & 0 & 1 & 1 & 0 \\
\hline \hline
\end{tabular}

PWM technique is shown in Table II, where 1 represents on, and 0 represents off.

For CHBMI, the number of output levels $(m)$ is always odd. The number of output voltage levels from CHBMI is given in (1), and the number of the switch $(X)$ can be derived in (2), where $N$ is the number of series-connected H-bridge power cells and $n$ is the number of carrier.

$$
\begin{gathered}
m=2 N+1=n+1 \\
X=2(m-1)
\end{gathered}
$$

LS-PWM and phase-shifted PWM (PS-PWM) are usually used for carrier-based PWM methods. LS-PWM has lower input current and output voltage distortion comparing with PSPWM. There are three types in the LS-PWM method because of space and phase differences: PD PWM, phase opposite disposition (POD) PWM, and alternate phase opposite disposition (APOD) PWM. These control strategies generate slightly different output waveforms, which are reflected in the change of the harmonic spectrum. The PD PWM has better harmonic performance than the other two methods [27]-[28]. Therefore, PD PWM is selected as the control strategy in the paper.

\section{B. Analysis of Fault Characteristics}

The following terminologies are defined: the OC fault occurred in the switch $\mathrm{S}_{x}$ is represented as $\mathrm{S}_{x o c}$; the load current is represented as $i_{1}$, and it is negative to the left and positive to the right; the output voltage of the H-bridge 1 and 2 is represented as $v_{\mathrm{o} 1}$ and $v_{\mathrm{o} 2}$; the CHBMI output voltage and current is represented as $v_{\mathrm{o} \mid \mathrm{oc}}$ which can be derived in (3) and $i_{\mathrm{l} \mid \mathrm{oc}}$ during 


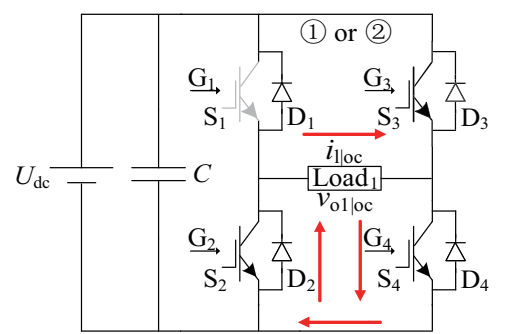

(a)

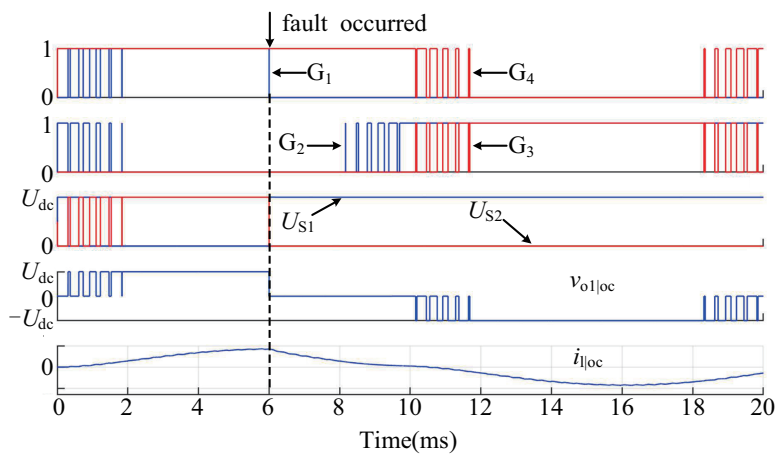

(c)
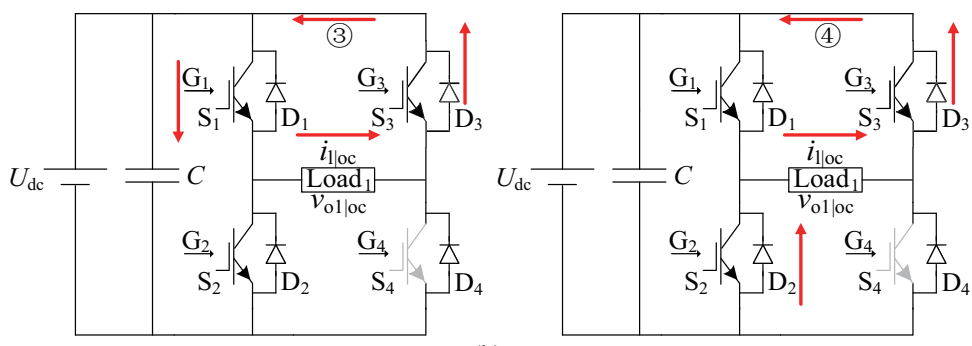

(b)

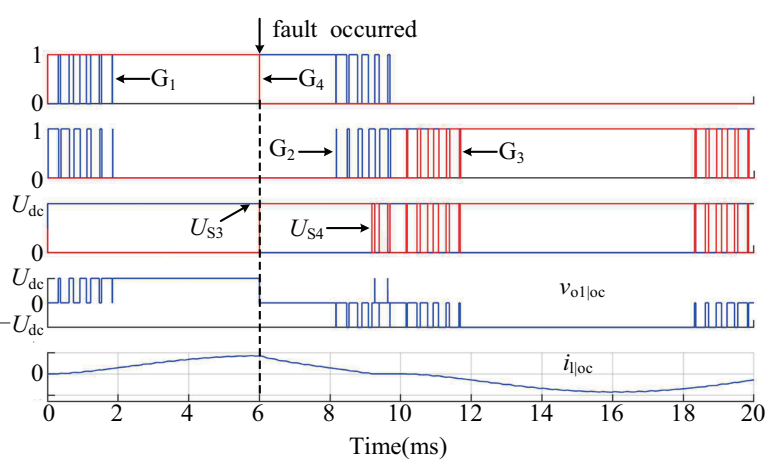

(d)

Fig. 2. Fault characteristics of $\mathrm{S}_{1 \mathrm{oc}}$ and $\mathrm{S}_{40 \mathrm{c}}$. (a) Load current path under $\mathrm{S}_{1 \mathrm{oc}}$. (b) Load current path under $\mathrm{S}_{40 \mathrm{c}}$. (c) The relationship between the four driving signals, the switch voltage in $\mathrm{S}_{1}$ and $\mathrm{S}_{2}$, the output voltage $\left(v_{\text {ol loc }}\right)$ and load current under $\mathrm{S}_{1 \text { oc }}$. (d) The relationship between the four driving signals, the switch voltage in $\mathrm{S}_{3}$ and $\mathrm{S}_{4}$, the output voltage $\left(v_{\mathrm{ol} \mid \mathrm{oc}}\right)$ and load current under $\mathrm{S}_{4 \mathrm{oc}}$.

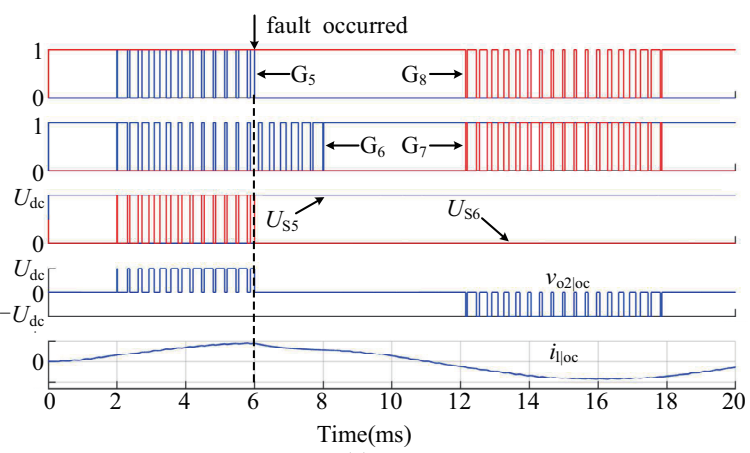

(a)

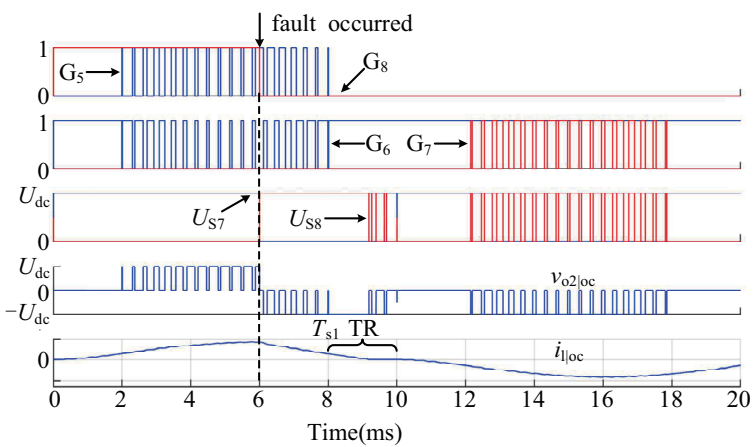

(b)

Fig. 3. Fault characteristics of $\mathrm{S}_{5 \mathrm{oc}}$ and $\mathrm{S}_{8 \mathrm{oc}}$. (a) The relationship between the four driving signals, the switch voltage in $\mathrm{S}_{5}$ and $\mathrm{S}_{6}$, the output voltage $\left(v_{\mathrm{o} 2 \mathrm{oc}}\right)$ and load current under $S_{50 c}$ (b) The relationship between the four driving signals, the switch voltage in $\mathrm{S}_{7}$ and $\mathrm{S}_{8}$, the output voltage $\left(v_{\mathrm{o} 2 \mathrm{oc}}\right)$ and load current under $\mathrm{S}_{8 \mathrm{oc}}$

the fault respectively. The influence of OC fault on the output voltage can be reflected on the output voltage of the H-bridge where the fault switch is located. At this time, it is assumed that two H-bridges start to work simultaneously, so a load $\left(\operatorname{Load}_{1}\right)$ is assumed on H-bridge 1 to analyze the current direction conveniently. The fault characteristics of the H-bridge will be analyzed in the following sections.

$$
v_{\mathrm{o} \mid \mathrm{oc}}=v_{\mathrm{o} 1 \mid \mathrm{oc}}+v_{\mathrm{o} 2 \mid \mathrm{oc}}
$$

Where $v_{\text {ol oc }}$, and $v_{\mathrm{o} 2 \mathrm{loc}}$ are the output voltage of the H-bridge 1 and 2 during the fault.

For the CHBMI, $\mathrm{S}_{1}$ and $\mathrm{S}_{4}$ are taken as examples, and the analyses of other switches are similar. Fig. 2 shows the fault characteristics of $S_{10 c}$ and $S_{40 c}$. The red arrows in Fig. 2 are load current paths, and they can not be omitted. The following is a detailed analysis of the fault characteristics of $\mathrm{S}_{1}$ and $\mathrm{S}_{4}$.

The switching waveforms under $\mathrm{S}_{10 \mathrm{C}}$ can be discussed for two cases as follows:

1) $\mathrm{S}_{1}=\mathrm{S}_{4}=1, \mathrm{~S}_{2}=\mathrm{S}_{3}=0$, the switch voltages across $U_{\mathrm{S} 1} \approx$ $U_{\mathrm{dc}}, U_{\mathrm{S} 2} \approx 0, v_{\mathrm{olloc}} \approx 0, i_{\mathrm{lloc}}>0$.

2) $\mathrm{S}_{2}=\mathrm{S}_{4}=1, \mathrm{~S}_{1}=\mathrm{S}_{3}=0$, the switch voltages across $U_{\mathrm{S} 1} \approx$ $U_{\mathrm{dc}}, U_{\mathrm{S} 2} \approx 0, v_{\mathrm{olloc}} \approx 0, i_{\mathrm{lloc}}>0$.

The load current path is same in either case. Also, the switching waveforms under $\mathrm{S}_{4 \mathrm{OC}}$ can be divided into two cases and analyzed as follows:

3) $\mathrm{S}_{1}=\mathrm{S}_{4}=1, \mathrm{~S}_{2}=\mathrm{S}_{3}=0$, the switch voltages across $U_{\mathrm{S} 3} \approx$ $0, U_{\mathrm{S} 4} \approx U_{\mathrm{dc}}, v_{\mathrm{ol} \mid \mathrm{oc}} \approx 0, i_{\mathrm{lloc}}>0$.

4) $\mathrm{S}_{2}=\mathrm{S}_{4}=1, \mathrm{~S}_{1}=\mathrm{S}_{3}=0$, the switch voltages across $U_{\mathrm{S} 3} \approx$ $0, U_{\mathrm{S} 4} \approx U_{\mathrm{dc}}, v_{\mathrm{olloc}} \approx-U_{\mathrm{dc}}, i_{\mathrm{loc}}>0$.

The above squiggly equals sign is generated by taking into account the on-state voltage drop of the diode. 


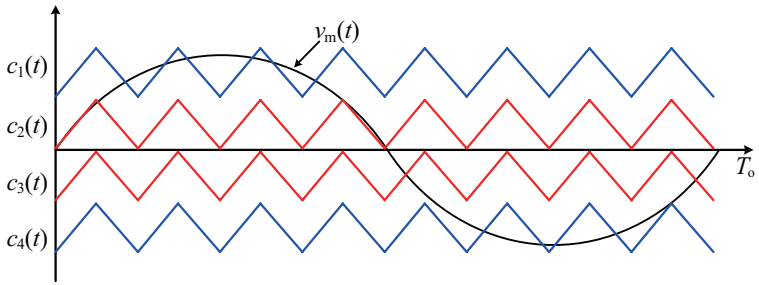

Fig. 4. The PD LS-PWM signals.

TABLE III

WORKING MoDES

\begin{tabular}{lllll}
\hline \hline Working modes & Mode 1 & Mode 2 & Mode 3 & Mode 4 \\
\hline$v_{\mathrm{m}}$ & positive & negative & positive & negative \\
$i_{1}$ & positive & negative & negative & positive \\
\hline \hline
\end{tabular}

Fig. 2 (a) and (b) shows the load current path under $\mathrm{S}_{\text {loc }}$ and $\mathrm{S}_{40 \mathrm{c}}$. The variation of the output voltage in the H-bridge 1 under $\mathrm{S}_{\mathrm{Ioc}}$ and $\mathrm{S}_{4 \mathrm{oc}}$ can be seen in Fig. 2 (c) and (d), respectively. The variation of the output voltage in the H-bridge 2 under $\mathrm{S}_{50 c}$ and $\mathrm{S}_{80 \mathrm{c}}$ can be seen in Fig. 3 (a) and (b), respectively.

The five-level inverter output voltage is generated by four level-shifted carriers in a phase-disposition (PD) pattern. The generation of PD LS-PWM signals is shown in Fig. 4, where the driving signals are the result of a comparison between the modulating sinusoidal signal $v_{m}(t)$ and four amplitude shifted high-frequency triangular carrier signals $c_{1}(t)-c_{4}(t)$. The healthy operation of CHBMI with inductive load can be divided into four working modes according to the voltage and current characteristics as shown in Table III, where $v_{m}$ is the modulating sinusoidal signal and $i_{1}$ is the load current. The CHBMI is only running in these four modes with inductive load under normal circumstances. The output voltage of the faulty H-bridge, load current, and the corresponding working mode under $\mathrm{S}_{1 \mathrm{loc}}-\mathrm{S}_{80 \mathrm{c}}$ are shown in Fig. 5.

As shown in Fig. 5, the diagonal switches show fault characteristics in the same working mode for each H-bridge (the red rectangle) in fault. It only needs to detect the fault in the two modes (mode 1,2), which significantly reduces the calculation of the system. In order to distinguish diagonal fault switches in the same working mode, the following fault characteristics are found through the above analysis: the value of $v_{\mathrm{olloc}} \approx 0$ if $\mathrm{G}_{1}=$ 0 under $\mathrm{S}_{1 \mathrm{oc}}$; the value of $v_{\mathrm{ol} / \mathrm{oc}} \approx 0$ if $\mathrm{G}_{1}=1$ and $v_{\mathrm{ol} \mathrm{loc}} \approx-U_{\mathrm{dc}}$ if $\mathrm{G}_{1}$ $=0$ under $\mathrm{S}_{40}$; the value of $v_{\mathrm{ol} l \mathrm{oc}} \approx 0$ if $\mathrm{G}_{3}=1$ and $v_{\mathrm{ol} l \mathrm{oc}} \approx U_{\mathrm{dc}}$ if $\mathrm{G}_{3}=0$ under $\mathrm{S}_{20 \mathrm{c}}$; the value of $v_{\mathrm{ol} \mathrm{loc}} \approx 0$ if $\mathrm{G}_{3}=0$ under $\mathrm{S}_{30 \mathrm{c}}$; the value of $v_{0210 c} \approx 0$ if $\mathrm{G}_{5}=0$ under $\mathrm{S}_{500}$; the value of $v_{\mathrm{o} 2 \mathrm{oc}} \approx 0$ if $\mathrm{G}_{5}$ $=1$ and $v_{0210 \mathrm{cc}} \approx-U_{\mathrm{dc}}$ if $\mathrm{G}_{5}=0$ under $\mathrm{S}_{8 \mathrm{oc}}$; the value of $v_{021 \mathrm{oc}} \approx 0$ if $\mathrm{G}_{7}=1$ and $v_{\mathrm{o} 2 \mathrm{oc}} \approx U_{\mathrm{dc}}$ if $\mathrm{G}_{7}=0$ under $\mathrm{S}_{60 \mathrm{c}}$; the value of $v_{\mathrm{o} 2 \mathrm{oc}} \approx 0$ if $\mathrm{G}_{7}=0$ under $\mathrm{S}_{70 \mathrm{co}}$. However, for the H-bridge 2, when the fault occurs in the time range (TR) as shown in Fig. 3 (b), the above diagnosis characteristics based on the driving signals are no longer applicable considering the system error. The start time of TR is defined as $T_{\mathrm{s} 1}$ and $T_{\mathrm{s} 2}$ for $\mathrm{S}_{6}, \mathrm{~S}_{7}$. It is the current fluctuation that causes the voltage change during TR. By amplifying the load current and the bridge arm voltage as shown in Fig. 5, we can find the following fault characteristics: the value of $v_{0210 c} \approx 0$

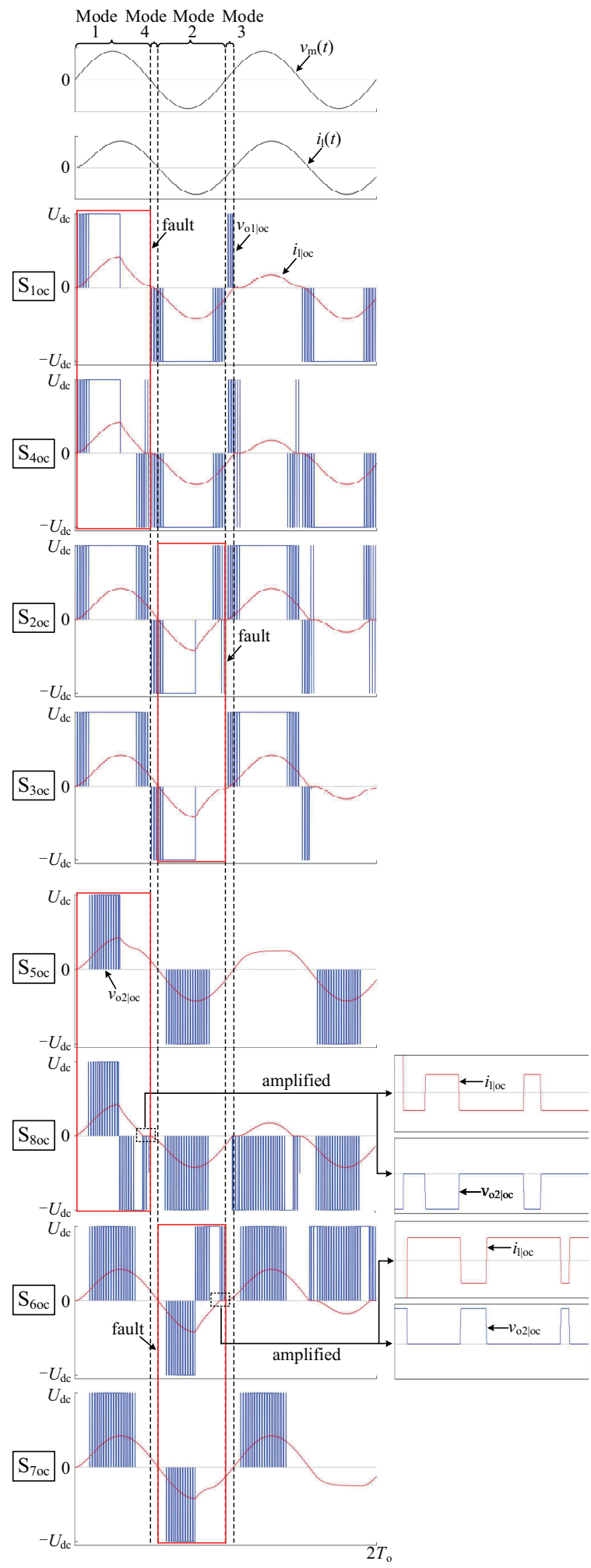

Fig. 5. Fault characteristics and working modes under $\mathrm{S}_{10 \mathrm{c}}-\mathrm{S}_{80 \mathrm{cc}}$.

if $i_{1 \mathrm{loc}}>0$ and $v_{\mathrm{o} 2 \mathrm{oc}} \approx U_{\mathrm{dc}}$ if $i_{\mathrm{loc}}<0$ under $\mathrm{S}_{60 \mathrm{co}}$; the value of $v_{\mathrm{o} 2 \mathrm{loc}} \approx$ 0 if $i_{\mathrm{loc}}<0$ and $v_{\mathrm{o} 2 / \mathrm{loc}} \approx-U_{\mathrm{dc}}$ if $i_{\mathrm{lloc}}>0$ under $\mathrm{S}_{8 \mathrm{oc}}$.

\section{The Proposed Fault Diagnosis Method}

Based on the analysis of switch fault characteristics, the 


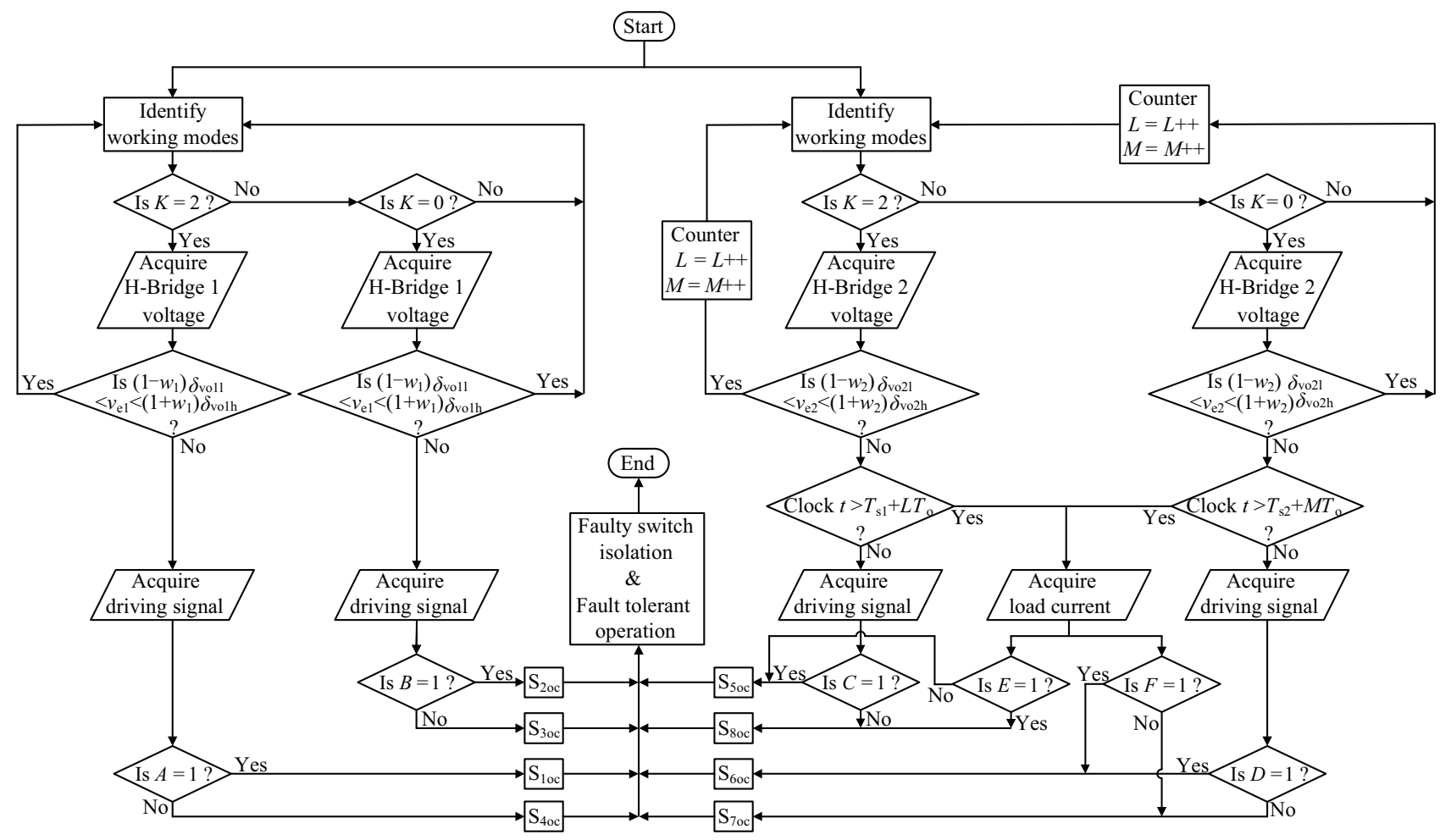

Fig. 6. Proposed fault diagnosis method.

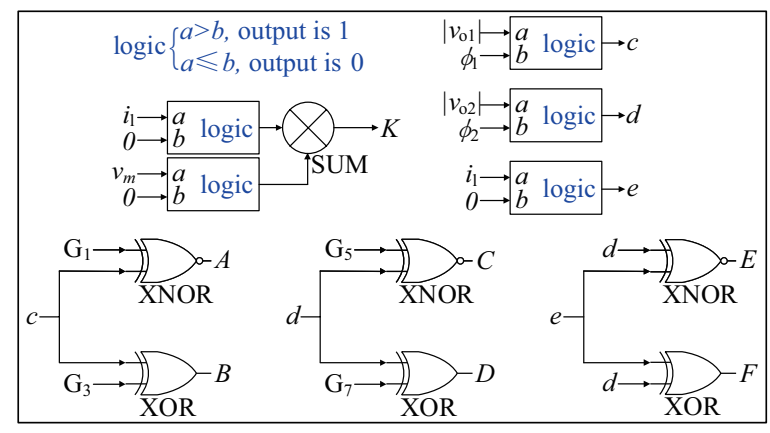

Fig. 7. The generation of $A-F$ and $K$.

proposed fault diagnosis method is shown in Fig. 6. The fault diagnosis method is developed for load current $i_{1}$, the output voltage of each $\mathrm{H}$-bridge, corresponding error $v_{\mathrm{e} 1}$ and $v_{\mathrm{e} 2}$, and respective driving signals considering inductive load, where $v_{\mathrm{e} 1}$ and $v_{\mathrm{e} 2}$ are the unit resultant of actual $\mathrm{H}$-bridge output voltage to reference $\mathrm{H}$-bridge output voltage. The generation of $A-F$ and $K$ is shown in Fig. 7. With regard to $v_{\mathrm{e} 1}$ and $v_{\mathrm{e} 2}$, they usually vary in a range; $v_{\mathrm{el}}$ belongs to the range from $v_{\mathrm{o} 11}$ to $v_{\mathrm{olh}}$, and $v_{\mathrm{e} 2}$ pertains to the range from $v_{\mathrm{o} 21}$ to $v_{\mathrm{o} 2 \mathrm{~h}}$ in the healthy operation. $f_{1}$ and $f_{2}$ are constantly associated with system parameters. In order to improve reliability, $w_{1}$ and $w_{2}$ are taken as $2.5 \%$ and $3 \%$ respectively in this paper, where $w_{1}$ and $w_{2}$ are considered as the margin of error variation.

Whether it's H-bridge 1 or 2, make an identification on the working modes firstly. All diagnoses are made under mode 1 or 2. When the detection condition is not satisfied, that is $K=1$, the H-bridge output voltage does not need to be detected, and
TABLE IV

SYSTEM PARAMETERS

\begin{tabular}{lcc}
\hline \hline Symbol & Parameters & Value \\
\hline$U_{\mathrm{dc}}$ & DC voltage & $40 \mathrm{~V}$ \\
$f_{\mathrm{o}}\left(=1 / T_{\mathrm{o}}\right)$ & Fundamental frequency & $50 \mathrm{~Hz}$ \\
$f_{\mathrm{c}}$ & Carrier frequency & $3 \mathrm{kHz}$ \\
$L_{\mathrm{f}}$ & Filter inductance & $9.5 \mathrm{mH}, 0.35 \Omega$ \\
$C_{\mathrm{f}}$ & Filter capacitor & $10 \mu \mathrm{F}, 0.03 \Omega$ \\
$C$ & Voltage stabilizing capacitance & $20 \mathrm{mF}$ \\
$M$ & Modulation index & 0.9 \\
$Z_{\mathrm{L}}$ & Load impedance & $8 \Omega, 9 \mathrm{mH}$ \\
\hline \hline
\end{tabular}

TABLE V

Parameters of the Control Loop

\begin{tabular}{lcc}
\hline \hline Symbol & Parameters & Value \\
\hline$K_{\mathrm{vp}}$ & Proportion index of voltage loop & 0.1 \\
$K_{\mathrm{vi}}$ & Integration index of voltage loop & 4.5 \\
$K_{i \mathrm{p}}$ & Proportion index of current loop & 0.01 \\
$K_{i \mathrm{i}}$ & Integration index of current loop & 0.01 \\
\hline
\end{tabular}

the corresponding counter need to work, so the computation of the control system is greatly reduced. When the detection condition ( $K=0$ or 2 ) is satisfied, the output voltage of the $\mathrm{H}$-bridge needs to be detected to judge whether it is beyond the error range to obtain the corresponding driving signals. However, for the H-bridge 2, when the output voltage meets the 

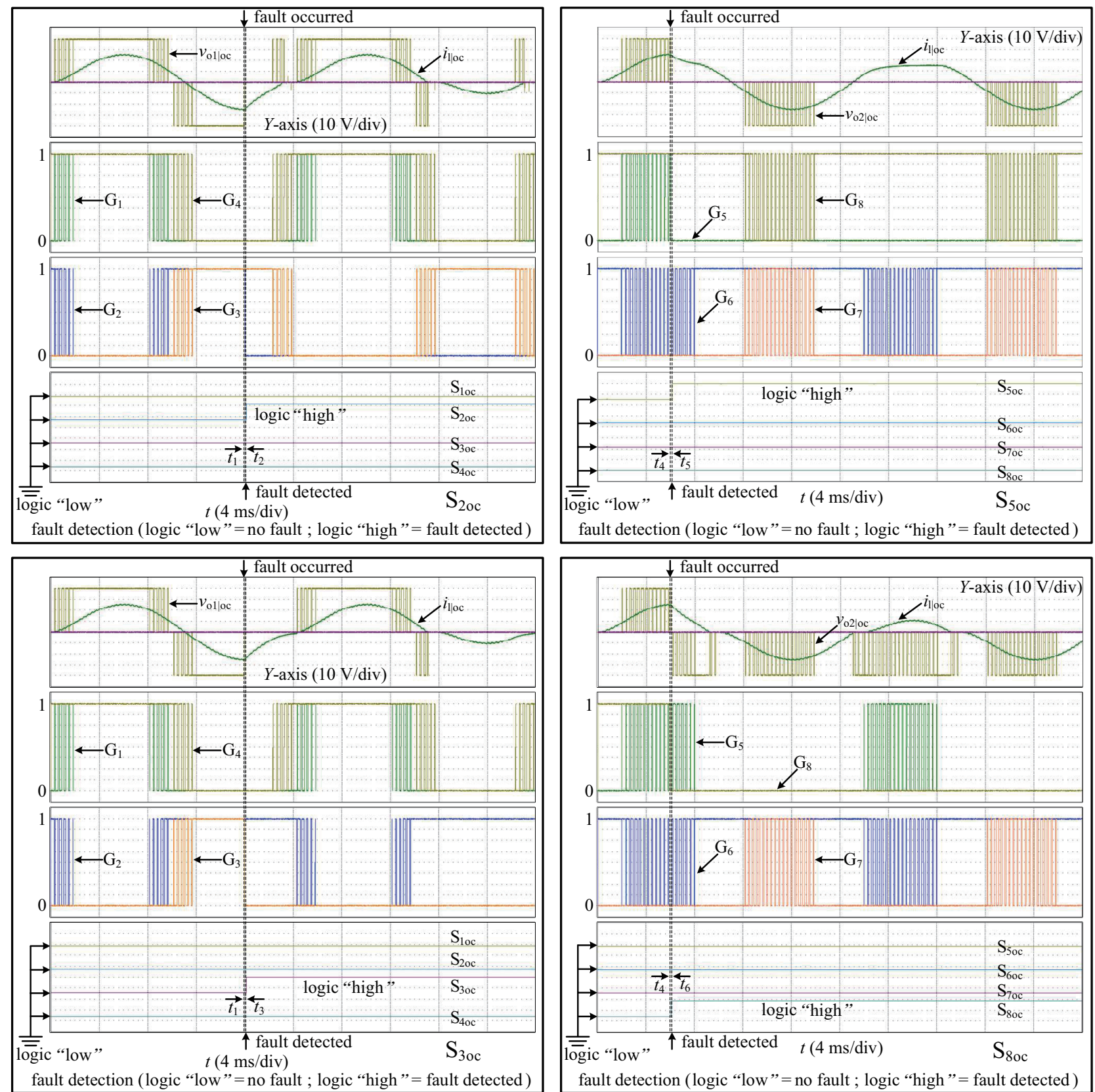

Fig. 8. H-bridge output voltage, load current, driving signals and fault dectection signal under $\mathrm{S}_{200}, \mathrm{~S}_{30 c}$, and $\mathrm{S}_{500}, \mathrm{~S}_{80 \mathrm{c}}\left(f_{c}=3 \mathrm{kHz}\right)$.

detection conditions, judge the detected time range through the clock and counter first to determine whether the load current needs to be detected. Finally, the fault diagnosis is carried out according to the detected voltage, load current, and corresponding driving signals. After the fault switch is diagnosed, faulty switch isolation and fault-tolerant operation is put into effect to ensure the safe and stable operation of the system.

\section{EXPERIMENT ANALYSIS}

Experiments have been carried out to prove the effectiveness of the proposed fault diagnosis method. The system parameters are detailed in Table IV. Parameters for the control system are given in Table V. System control and fault diagnosis are pro- cessed with DSP TMS320F28335. By giving an external interrupt signal to DSP, the PWM signal that needs to turn off the switch is changed to a low level to realize the given OC fault. Meanwhile, set a certain delay in the logic detection module to consider the sensors' dynamic delay. $\mathrm{S}_{20 \mathrm{c}}, \mathrm{S}_{30 \mathrm{c}}$, and $\mathrm{S}_{50 \mathrm{c}}, \mathrm{S}_{8 \mathrm{oc}}$ are taken as examples for verification.

The waveforms of $\mathrm{H}$-bridge output voltage, load current, driving signals, and fault detection signal under $\mathrm{S}_{200}, \mathrm{~S}_{300}$, and $\mathrm{S}_{50 \mathrm{c}}, \mathrm{S}_{80 \mathrm{cc}}$ are presented in Fig. 8. For $\mathrm{S}_{20 \mathrm{c}}, \mathrm{S}_{30 \mathrm{c}}$, and $\mathrm{S}_{50 \mathrm{cc}}, \mathrm{S}_{80 \mathrm{c}}$, fault occur at $t=t_{1}$ and $t_{4}$, respectively. At $t=t_{2}, t_{3}, t_{5}, t_{6}$, the fault is detected accordingly. Similarly, other switches have also achieved the same diagnostic results. All OC faults can be detected within one switching interval. Time of fault and time of fault detection under different switching frequencies $\left(f_{\mathrm{sw}}\right.$ 
TABLE VI

Time of Fault and Time of Fault Detection Under Different Switching Frequency

\begin{tabular}{|c|c|c|c|c|c|c|c|}
\hline \multicolumn{4}{|c|}{$S_{2 o c}$} & \multicolumn{4}{|c|}{$\mathrm{S}_{3 o c}$} \\
\hline \multirow{2}{*}{ Time of fault (ms) } & \multicolumn{3}{|c|}{ Time of fault detection (ms) } & \multirow{2}{*}{ Time of fault (ms) } & \multicolumn{3}{|c|}{ Time of fault detection (ms) } \\
\hline & $f_{\mathrm{c}}=3 \mathrm{kHz}$ & $f_{\mathrm{c}}=5 \mathrm{kHz}$ & $f_{\mathrm{c}}=7 \mathrm{kHz}$ & & $f_{\mathrm{c}}=3 \mathrm{kHz}$ & $f_{\mathrm{c}}=5 \mathrm{kHz}$ & $f_{\mathrm{c}}=7 \mathrm{kHz}$ \\
\hline 16 & 0.1122 & 0.1125 & 0.1127 & 16 & 0.1119 & 0.1121 & 0.1126 \\
\hline 16.5 & 0.1123 & 0.1123 & 0.1128 & 16.5 & 0.1117 & 0.1123 & 0.1126 \\
\hline 17 & 0.1122 & 0.1126 & 0.1129 & 17 & 0.1119 & 0.1124 & 0.1128 \\
\hline 17.5 & 0.1120 & 0.1124 & 0.1126 & 17.5 & 0.1120 & 0.1123 & 0.1127 \\
\hline 18 & 0.1121 & 0.1125 & 0.1127 & 18 & 0.1118 & 0.1123 & 0.1126 \\
\hline Average & 0.11216 & 0.11246 & 0.11274 & Average & 0.11186 & 0.11228 & 0.11266 \\
\hline \multicolumn{4}{|c|}{$\mathrm{S}_{5 \mathrm{oc}}$} & \multicolumn{4}{|c|}{$\mathrm{S}_{80 c}$} \\
\hline \multirow{2}{*}{ Time of fault (ms) } & \multicolumn{3}{|c|}{ Time of fault detection (ms) } & \multirow{2}{*}{ Time of fault (ms) } & \multicolumn{3}{|c|}{ Time of fault detection (ms) } \\
\hline & $f_{\mathrm{c}}=3 \mathrm{kHz}$ & $f_{\mathrm{c}}=5 \mathrm{kHz}$ & $f_{\mathrm{c}}=7 \mathrm{kHz}$ & & $f_{\mathrm{c}}=3 \mathrm{kHz}$ & $f_{\mathrm{c}}=5 \mathrm{kHz}$ & $f_{\mathrm{c}}=7 \mathrm{kHz}$ \\
\hline 6 & 0.1119 & 0.1124 & 0.1127 & 6 & 0.1121 & 0.1126 & 0.1128 \\
\hline 6.5 & 0.1118 & 0.1123 & 0.1127 & 6.5 & 0.1122 & 0.1126 & 0.1129 \\
\hline 7 & 0.1119 & 0.1123 & 0.1126 & 7 & 0.1122 & 0.1124 & 0.1129 \\
\hline 7.5 & 0.1119 & 0.1123 & 0.1128 & 7.5 & 0.1123 & 0.1126 & 0.1126 \\
\hline 8 & 0.1121 & 0.1124 & 0.1126 & 8 & 0.1121 & 0.1125 & 0.1127 \\
\hline Average & 0.11192 & 0.11234 & 0.11268 & Average & 0.11218 & 0.11254 & 0.11278 \\
\hline
\end{tabular}

$=2 N f_{\mathrm{c}}$ ) are shown in Table VI. From Table VI, we can find that the diagnosis time of the lower switch of each H-bridge is slightly longer than that of the corresponding upper switch by setting different fault times. This is caused by the same logic value generated by the corresponding driving signal and output voltage when the fault occurs, so the fault can not be detected immediately, and it usually does not exceed a switching interval. Moreover, the detection time will be appropriately longer within the error tolerance when the switching frequency increases.

\section{Conclusion}

In this paper, a fault diagnosis method for CHBMI based on the LS-PWM technique is proposed. The OC fault results in the incomplete vanishment of the faulty H-bridge voltage, which can be detected by the proposed method. The fault can be detected within one switching period from the H-bridge output voltage change with a healthy output voltage state. Since the CHBMI output characteristics under diagonally opposite switch fault characteristics are challenging to identify, this paper presents a detection method to identify each faulty switch in the CHBMI uniquely. For IGBT-based inverters with a high switching frequency, the related experimental results have been given to demonstrate the effectiveness of the proposed method. However, for SiC or GaN-based inverters, further experiments are needed to verify it. The proposed diagnosis method may be used for fault diagnosis of other multilevel inverters. Although the proposed method increases the number of sensors, it achieves the desired effect.

\section{REFERENCES}

[1] J. Pou, R. Pindado, and D. Boroyevich, "Voltage-balance limits in four-level diode-clamped converters with passive front ends," in IEEE Transactions on Industrial Electronics, vol. 52, no. 1, pp. 190-196, Feb. 2005.

[2] J. Zhao, Y. Han, X. He, C. Tan, J. Cheng, and R. Zhao, "Multilevel circuit topologies based on the witched-capacitor converter and diodeclamped converter," in IEEE Transactions on Power Electronics, vol. 26, no. 8, pp. 2127-2136, Aug. 2011.

[3] S. Alepuz, S. Busquets-Monge, J. Bordonau, J. Gago, D. Gonzalez, and J. Balcells, "Interfacing renewable energy sources to the utility grid using a three-level inverter," in IEEE Transactions on Industrial Electronics, vol. 53, no. 5, pp. 1504-1511, Oct. 2006.

[4] J. Rodriguez, S. Bernet, P. Steimer, and I. Lizama, "A survey on neutral point-clamped inverters," in IEEE Transactions on Industrial Electronics, vol. 57, no. 7, pp. 2219-2230, Jul. 2010.

[5] J. Yu, G. Zhang, M. Peng, D. Song, and M. Liu, "Power-matching based SOC balancing method for cascaded H-bridge multilevel inverter," in CPSS Transactions on Power Electronics and Applications, vol. 5, no. 4, pp. 352-363, Dec. 2020.

[6] J. Mathew, P. P. Rajeevan, K. Mathew, N. A. Azeez, and K. Gopakumar, "A multilevel inverter scheme with dodecagonal voltage space vectors based on flying capacitor topology for induction motor drives," in IEEE Transactions on Power Electronics, vol. 28, no. 1, pp. 516-525, Jan. 2013.

[7] S. M. Jung, J. S. Park, H. W. Kim, K. Y. Cho, and M. J. Youn, “An MRAS based diagnosis of open-circuit fault in PWM voltagesource inverters for PM synchronous motor drive systems," in IEEE Transactions on Power Electronics, vol. 28, no. 5, pp. 2514-2526, May 2013. 
[8] N. B. Y. Gorla, S. Kolluri, M. Chai, and S. K. Panda, "A novel opencircuit fault detection and localization scheme for cascaded H-bridge stage of a three-stage solid-state transformer," in IEEE Transactions on Power Electronics, vol. 36, no. 8, pp. 8713-8729, Aug. 2021.

[9] M. Chai, N. B. Y. Gorla, and S. K. Panda, "Fault detection and localization for cascaded H-bridge multilevel converter with model predictive control," in IEEE Transactions on Power Electronics, vol. 35, no. 10, pp. 10109-10120, Oct. 2020.

[10] A. B. de Mello Oliveira, R. L. Moreno, and E. R. Ribeiro, "Short-circuit fault diagnosis based on rough sets theory for a single-phase inverter," in IEEE Transactions on Power Electronics, vol. 34, no. 5, pp. 4747-4764, May 2019.

[11] B. Luand and S. K. Sharma, "A literature review of IGBT fault diagnostic and protection methods for power inverters," in IEEE Transactions on Industry Applications, vol. 45, no. 5, pp. 1770-1777, Sept.-Oct. 2009.

[12] N. M. A. Freire, J. O. Estima, and A. J. M. Cardoso, "Open-circuit fault diagnosis in PMSG drives for wind turbine applications," in IEEE Transactions on Industrial Electronics, vol. 60, no. 9, pp. 3957-3967, Sept. 2013.

[13] J. O. Estima and A. J. Marques Cardoso, "A new approach for real-time multiple open-circuit fault diagnosis in voltage-source inverters," in IEEE Transactions on Industry Applications, vol. 47, no. 6, pp. $2487-$ 2494, Nov.-Dec. 2011

[14] J. Zhang, J. Zhao, D. Zhou, and C. Huang, "High-performance fault diagnosis in PWM voltage-source inverters for vector-controlled induction motor drives," in IEEE Transactions on Power Electronics, vol. 29, no. 11, pp. 6087-6099, Nov. 2014.

[15] F. Wu and J. Zhao, "A real-time multiple open-circuit fault diagnosis method in voltage-source-inverter fed vector controlled drives," in IEEE Transactions on Power Electronics, vol. 31, no. 2, pp. 1425-1437, Feb. 2016.

[16] T. Kamel, Y. Biletskiy, and L. Chang, "Fault diagnoses for industrial grid-connected converters in the power distribution systems," in IEEE Transactions on Industrial Electronics, vol. 62, no. 10, pp. 6496-6507, Oct. 2015.

[17] T. Kamel, Y. Biletskiy, and L. Chang "Fault diagnosis and on-line monitoring for grid-connected single-phase inverters," in Electric Power Systems Research, vol. 126, pp. 68-77, 2015.

[18] X. Ge, J. Pu, and Y. Liu, "Online open-switch fault diagnosis method in single-phase PWM rectifiers," in Electronics Letters, vol. 51, pp. 1920-1922, Nov. 2015

[19] C. Choi and W. Lee, "Design and evaluation of voltage measurementbased sectoral diagnosis method for inverter open switch faults of permanent magnet synchronous motor drives," in IET Electric Power Applications, vol. 6, no. 8, pp. 526-532, Sept. 2012.

[20] C. Shu, C. Ya-Ting, Y. Tian-Jian, and W. Xun, "A novel diagnostic technique for open-circuited faults of inverters based on output line-to-line voltage model," in IEEE Transactions on Industrial Electronics, vol. 63, no. 7, pp. 4412-4421, Jul. 2016.

[21] M. A. Rodríguez-Blanco, A. Vázquez-Pérez, L. Hernández-González, V. Golikov, J. Aguayo-Alquicira, and M. May-Alarcón, "Fault detection for IGBT using adaptive thresholds during the turn-on transient," in IEEE Transactions on Industrial Electronics, vol. 62, no. 3, pp. 1975-1983, Mar. 2015.

[22] S. M. Jung, J. S. Park,H. W. Kim, K. Y. Cho, and M. J. Youn, “An MRAS-based diagnosis of open-circuit fault in PWM voltage-source inverters for PM synchronous motor drive systems," in IEEE Transactions on Power Electronics, vol. 28, no. 5, pp. 2514-2526, May 2013.

[23] Q. T An, L. Sun, and L. Z. Sun, "Current residual vector-based open switch fault diagnosis of inverters in PMSM drive systems," in IEEE Transactions on Power Electronics, vol. 30, no. 5, pp. 2814-2827, May 2015.

[24] N. M. A. Freire, J. O. Estima, and A. J. M. Cardoso, "A voltage-based approach without extra hardware for open-circuit fault diagnosisin closed loop PWM AC regenerative drives," in IEEE Transactions on Industrial Electronics, vol. 61, no. 9, pp. 4960-4970, Sept. 2014.

[25] I. Jlassi, J. O. Estima, S. Khojet El Khil, N. Mrabet Bellaaj, and A. J. Marques Cardoso, "Multiple open-circuit faults diagnosis in back-toback converters of PMSG drives for wind turbine systems," in IEEE Transactions on Power Electronics, vol. 30, no. 5, pp. 2689-2702, May 2015.

[26] M. Kumar, "Open circuit fault detection and switch identification for LSPWM H-bridge inverter," in IEEE Transactions on Circuits and Systems II: Express Briefs, vol. 68, no. 4, pp. 1363-1367, Apr. 2021.

[27] M. Kumar and R. Gupta, "Time-domain characterisation of multicarrierbased digital SPWM of multilevel VSI," in IET Power Electronics, vol. 11, no. 1, pp. 100-109, Jan. 2018.

[28] G. S. Konstantinou and V. G. Agelidis, "Performance evaluation of haifbridge cascaded multilevel converters operated with multicarrier sinusoidal PWM techniques," in Proceedings of 2009 4th IEEE Conference on Industrial Electronics and Applications, 2009, pp. 3399-3404.

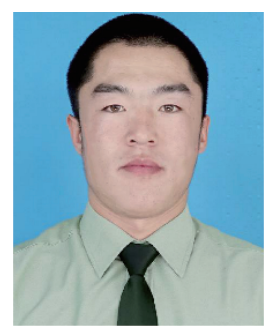

Gang Zhang was born in Ordos, China, in 1995. He received the B.E. degree in electrical engineering and automation from Central South University, Hunan, China, in 2020. He is currently pursuing the M.E. degree in electrical engineering at Central South University. His main research interests include fault diagnosis, fault tolerance and power electronics.

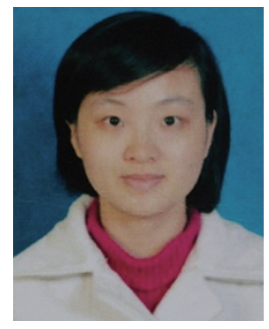

Jingrong Yu was born in Dandong, China, in 1981. She received the B.E. and Ph.D. degrees in control science and engineering from Hunan Univesity, Changsha, China, in 2004 and 2009, respectively. From 2014 to 2015, she was a Visiting Scholar with the Department of Electrical Engineering and Computer Science, the University of Tennessee, Knoxville. In 2009, she joined Central South University, where she is currently an Associate Professor. Her research interests include modeling and control of power electronic converters in renewable energy systems and microgrids, and analysis and control of power quality. 